\title{
A Terrestrial Reference Frame (TRF), coordinates and velocities for South American stations: contributions to Central Andes geodynamics
}

\author{
M. V. Mackern ${ }^{2,3}$, M. L. Mateo ${ }^{1,2}$, A. M. Robin ${ }^{1}$, and A. V. Calori ${ }^{1,2}$ \\ ${ }^{1}$ Consejo Nacional de Investigaciones Científicas y Técnicas, Mendoza, Argentina \\ ${ }^{2}$ Facultad de Ingeniería, Universidad Nacional de Cuyo, Mendoza, Argentina \\ ${ }^{3}$ Facultad de Ingeniería, Universidad Juan Agustín Maza, Mendoza, Argentina
}

Received: 30 April 2009 - Revised: 13 November 2009 - Accepted: 17 November 2009 - Published: 17 December 2009

\begin{abstract}
Satellite positioning systems allow the fixing of the location of a point on the Earth's surface with very good precision and accuracy. To do this, however, it is necessary to determine the point coordinates taking account the reference system and the movements that affect them because of tectonic plate movements. These reference systems are materialized by a significant number of continuous measurement stations in South America. In SIRGAS (Sistema de Referencia Geocéntrico para las Américas), there are four Analysis Centers that process the data collected from satellites of the Global Navigation Satellite Systems (GNSS), with the primary purpose to maintain the international terrestrial reference frame through calculation of the coordinates and velocities of the continuous GNSS stations of the SIRGAS-CON Network.

In this work, we demonstrate the quality of the solutions from CIMA, one of the SIRGAS official processing centers operating in Mendoza, Argentina, in comparison with other South American processing centers. The importance of precise calculations of coordinates and velocities in a global frame is also shown. Finally, we give estimations of velocities from stations located within deformation zones in the Central Andes.
\end{abstract}

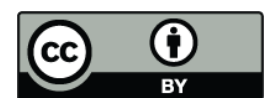

Correspondence to: M. L. Mateo (lmateo@lab.cricyt.edu.ar)

\section{Introduction}

Geodetic measurements from Satellite Laser Ranging (SLR), Very Long Baseline Interferometry (VLBI) and Global Navigation Satellite Systems (GNSS) are a valuable source of information for understanding geodynamics processes such as crustal deformation, post-glacial rebound, Earth rotation irregularities, etc. (Drewes, 2006). A critical prerequisite to extract reliable geodynamics signals from time series of geodetic coordinates is to ensure the accuracy and the longterm stability of the Terrestrial Reference Frame (TRF) to which the geodetic coordinates are referenced (Altamimi et al., 2007; Angermann et al., 2007). Millimeter-level accuracy and stability over years are needed to ensure that coordinates changes with time are truly related to geodynamics processes rather than to TRF instabilities. Moreover, TRF instabilities may propagate to the geodetic coordinates through the satellite orbits, which are determined on observations collected from terrestrial tracking stations whose precise coordinates are also referenced to the same TRF.

SIRGAS (Sistema de referencia Geocéntrico para las Américas) contributes to the TRF for the Caribbean, Central and South American regions, using the highest standards of modern geodesy (Sánchez and Brunini, 2009). The SIRGAS TRF consists of more than 200 continuously operating GNSS stations (SIRGAS-CON network), which are grouped into four sub-networks: a continental one (SIRGASCON-C) with about 100 stations homogeneously distributed over Latin America and the Caribbean, and three densification sub-networks (SIRGAS-CON-D) covering the northern, middle, and the southern parts of the SIRGAS region. Data of each sub-network are processed by one of the SIRGAS

Published by Copernicus Publications on behalf of the European Geosciences Union. 


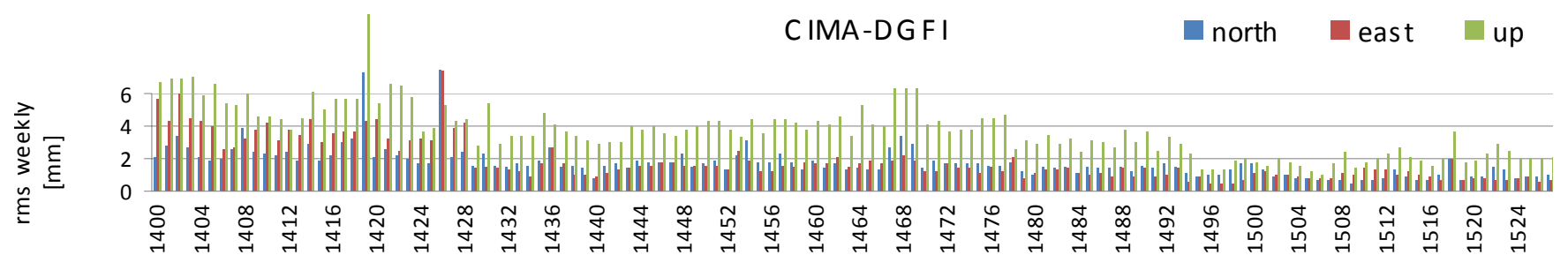

GPS week

Fig. 1. Agreement between the loosely constrained weekly solutions calculated by CIMA and DGFI.

Processing Centres: Deutsches Godätisches Forschungsinstitu (DGFI - Germany) is responsible for the SIRGASCON-C network; Instituto Geográfico Agustín Codazzi (IGAC - Colombia) for the northern denser sub-network; Instituto Brasileiro de Geogarfia e Estatistica (IBGE - Brazil) for the middle one; and Centro Ingeniería Mendoza Argentina (CIMA - Argentina) for the southern one (see the site distribution in the Fig. 3). Each Processing Centre delivers weekly solutions that are integrated into a unified solution by the SIRGAS Combination Centres operating at DGFI and IBGE. The DGFI combinations are made available to users as official SIRGAS weekly reference frame solutions, while the IBGE weekly combinations provide control and redundancy.

This paper describes the processing methodology used by CIMA, emphasizing the rigorous procedures applied to ensure the reliability of the weekly solutions computed by this centre. These weekly solutions encompass around ninety stations (presently fifty eight) distributed all over the southern part of the South American Continent and provide, at the same time, the best TRF available in the region and an accurate determination of the three-dimensional velocity of the measured points, which reflect the present crustal deformation of the region (Seemüller, 2009).

\section{Processing methodology}

Since 2006, CIMA has been charged with the computation of the sites of the southern SIRGAS-CON-D network (58 at present). The raw GNSS data are processed with the Bernese 5.0 software (Dach et al., 2007). The main standards of this process (see e.g., Natali et al., 2009) include an elevation mask of $3^{\circ}$; sampling rate of $30 \mathrm{~s}$; IGS absolute calibration values for the antenna phase centre corrections; IGS weekly values for satellite orbits, satellite clock offsets, and Earth orientation parameters; and ocean-tide loading corrections derived from the FES2004 model. Additionally, the zenith delay due to the neutral atmosphere refraction is estimated at a $2 \mathrm{~h}$ interval within the network adjustment.

The output of this processing is a daily normal equation system whose unknowns are the position coordinates, the carrier phase ambiguities, and the zenith delays. These normal equations are termed "loosely constrained" in order to stress that the position coordinate unknowns are statistically constrained to be identical to given a-priory values within a standard deviations of $\pm 1 \mathrm{~m}$. This constraint is tight enough to avoid the singularity of the normal system, but loose enough to avoid distortions in the network due to datum inconsistencies.

The undesired unknowns (i.e., the carrier phase ambiguities and the zenith delays) are reduced and the daily normal systems are stacked in a weekly normal system, whose solution provides the loosely constrained weekly coordinates of the network. The first control applied to this process consists of a comparison with the corresponding loosely constrained weekly coordinates computed by DGFI and IBGE. This comparison is performed by means of a seven-parameter similarity transformation between the common coordinates in the different solutions. The residuals of this similarity transformation provide the first estimate of the network precision.

All weekly normal systems from 6 November 2006 to 13 April 2009, were then stacked in a multiannual normal system whose solution provided the position coordinates and velocities presented in this paper. At this stage, only the sites with more than one uninterrupted year of data were considered. In order to solve this multiannual normal system, the coordinate velocities, $V_{X}$, were constrained to be constant, so that the position coordinates for any given time, $T$, are related to the position coordinates at a reference epoch, $T_{0}$, by the linear relation $X(T)=X\left(T_{0}\right)+V_{X} \cdot\left(T-T_{0}\right)$. In addition, the position-coordinate unknowns of 11 stations (BRAZ, CHPI, CONZ, CRO1, GLPS, ISPA, LPGS, MANA, SANT, SCUB and UNSA) where constrained to be identical to the values provided by the IGS05 solution (translated to the reference epoch with constant velocities) within a small standard deviation (http://igscb.jpl.nasa.gov/network/ refframe.html). The reference epoch for this work was taken at the middle of the observing periods, i.e.: 2008.0.

\section{Results}

We have obtained a time series of 127 weekly solutions (2 years and 5 month). Figures 1 and 2 show the comparisons of coordinate solutions between CIMA-DGFI and CIMA- 


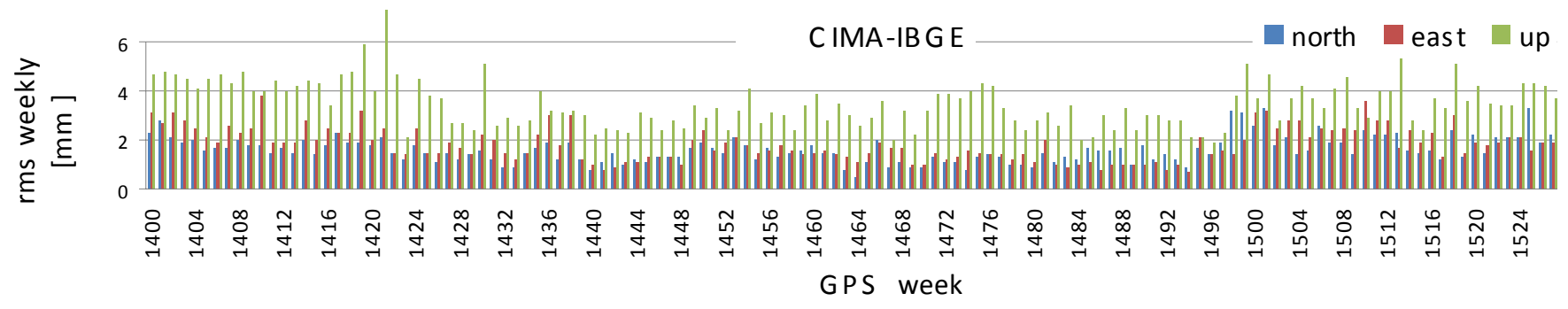

Fig. 2. Agreement between the loosely constrained weekly solutions calculated by CIMA and IBGE.

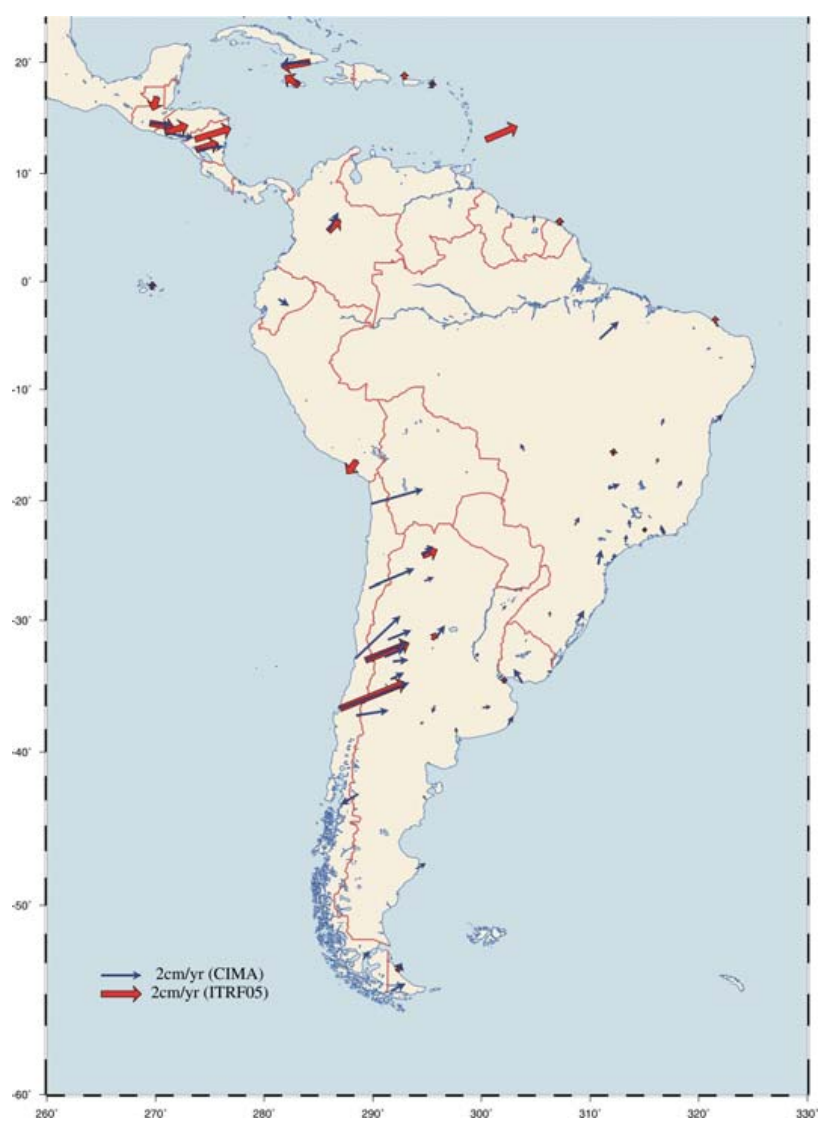

Fig. 3. Comparison of velocity vectors obtained by CIMA and ITRF2005 relative to the South American plate.

IBGE, respectively. The precision of CIMA weekly solution is estimated to be $\pm 2 \mathrm{~mm}$ in the horizontal components and $4 \mathrm{~mm}$ in height.

The coordinates of 92 stations distributed by South America were calculated. The precision of coordinates for the reference epoch is estimated to be $\pm 0.5 \mathrm{~mm}$ in horizontal components and $\pm 0.9 \mathrm{~mm}$ in height.

Velocities were then estimated for stations with at least one year of observations (75 stations). Stations with fewer observations received only a coordinate solution. The precision of velocities we determined is about $\pm 0.9 \mathrm{~mm} /$ year.
In order to characterize the deformations zones the estimated velocities were reduced with respect to the South America (SOAM) plate. The model used was NNRNUVEL1A (De Mets et al., 1994). Figure 3 shows the deformations in the stations of the region.

\section{Conclusions}

For South America, the TRF (SIRGAS) provides a precision of measured coordinates estimated to be $\pm 0.5 \mathrm{~mm}$ in horizontal components and $\pm 0.9 \mathrm{~mm}$ in height (Seemüller, 2009). Thus, this TRF allows the referencing the positions of the measured sites and their variations with time with high precision.

Good correspondence exists for the observed deformations with respect to the SOAM plate motions between the velocities estimated by CIMA and those estimated by ITRF2005 (Fig. 3). Data resulting from the increased density of the IGS network in South America processed by CIMA have allowed a refined identification of the limits of deformations zones within the Central Andes. To further improve our understanding of the behavior of the western margin of South America, it would be necessary to incorporate into SIRGASCON the data for continuous GNSS stations in Bolivia, Peru and in the south of Argentina and Chile.

Acknowledgements. The authors express sincere thanks to Chuck De Mets and Michael Poland for their constructive reviews of an earlier version of this paper and helpful suggestions that strengthened the discussion and presentation of the data.

Edited by: B. Tilling

Reviewed by: C. De Mets, M. Poland and another anonymous referee

\section{References}

Altamimi, Z., Collilieux, X., Legrand, J., Garayt, B., and Boucher, C.: ITRF2005: A new release of the International Terrestrial Reference Frame based on time series of station positions and Earth Orientation Parameters, J. Geophys. Res., 112, B09401, doi:10.1029/2007JB004949, 2007. 
Angermann, D., Drewes, H., Krügel, M., and Meisel, B.: Advances in terrestrial reference frame computations, Springer, IAG Symposia, Vol. 130, 595-602, 2007.

Dach, R., Hugentobler, U., Fridez, P., and Meindl, M.: Bernese GPS Software version 5.0, Astronomical Institute, University of Berne, Switzerland, 2007.

DeMets, C., Gordon, R., Argus, D. F., and Stein, S.: Effect of recent revisions to the geomagnetic reversal time scale on estimates of current plate motions, Geophys. Res. Lett., 21, 2191-2194, 1994.

Drewes, H.: The science rationale of the Global Geodetic Observing System GGOS, in: Dynamic Planet - Monitoring and Understanding a Dynamic Planet with Geodetic and Oceanographic Tools, edited by: Tregoning, P. and Rizos, C., International Association of Geodesy Symposia, Vol. 130, Springer Verlag, Berlin, 2006..

Natali, M. P., Müller, M., Fernández, F., and Brunini, C.: CPLat: first operational Experimental Processing Center for SIRGAS in Argentina, J. Geodesy, 83, 219-226, doi:10.1007/s00190-0080270-5, 2009.
Sanchez, L., Seemüller, W., and Krügel, M.: Comparison and combination of the weekly solutions delivered by the SIRGAS Experimental Processing Centres, DGFI Report No. 80, Deutsches Geodätisches Forschungsinstitut (DGFI) Alfons-Goppel-Str. 11, Munich, Germany, 2008.

Sanchez, L. and Brunini, C.: Achievements and Challenges of SIRGAS, in: Geodetic Reference Frames, edited by: Drewes, H., International Association of Geodesy Symposia, 134, 161-166, doi:10.1007/978-3-642-00860-3_25, 2009.

Seemüller, W. L.: The Position and Velocity Solution DGF06P01 for SIRGAS, in: Geodetic Reference Frames, edited by: Drewes, H., IAG Symposia, Springer Verlag, Vol. 134, 167-172, 2009. 